\title{
Machine learning approach to support taxonomic species discrimination based on helminth collections data
}

\author{
Victor Hugo Borba ${ }^{1,2}$, Coralie Martin³, José Roberto Machado-Silva², Samanta C. C. Xavier ${ }^{1}$, \\ Flávio L. de Mello ${ }^{4}$ and Alena Mayo Iñiguez ${ }^{1 *}$ (D)
}

\begin{abstract}
Background: There are more than 300 species of capillariids that parasitize various vertebrate groups worldwide. Species identification is hindered because of the few taxonomically informative structures available, making the task laborious and genus definition controversial. Thus, its taxonomy is one of the most complex among Nematoda. Eggs are the parasitic structures most viewed in coprological analysis in both modern and ancient samples; consequently, their presence is indicative of positive diagnosis for infection. The structure of the egg could play a role in genera or species discrimination. Institutional biological collections are taxonomic repositories of specimens described and strictly identified by systematics specialists.

Methods: The present work aims to characterize eggs of capillariid species deposited in institutional helminth collections and to process the morphological, morphometric and ecological data using machine learning $(\mathrm{ML})$ as a new approach for taxonomic identification. Specimens of 28 species and 8 genera deposited at Coleção Helmintológica do Instituto Oswaldo Cruz (CHIOC, IOC/FIOCRUZ/Brazil) and Collection de Nématodes Zooparasites du Muséum National d'Histoire Naturelle de Paris (MNHN/France) were examined under light microscopy. In the morphological and morphometric analyses (MM), the total length and width of eggs as well as plugs and shell thickness were considered. In addition, eggshell ornamentations and ecological parameters of the geographical location (GL) and host $(\mathrm{H})$ were included.
\end{abstract}

Results: The performance of the logistic model tree (LMT) algorithm showed the highest values in all metrics compared with the other algorithms. Algorithm $\mathrm{J48}$ produced the most reliable decision tree for species identification alongside REPTree. The Majority Voting algorithm showed high metric values, but the combined classifiers did not attenuate the errors revealed in each algorithm alone. The statistical evaluation of the dataset indicated a significant difference between trees, with $\mathrm{GL}+\mathrm{H}+\mathrm{MM}$ and MM only with the best scores.

Conclusions: The present research proposed a novel procedure for taxonomic species identification, integrating data from centenary biological collections and the logic of artificial intelligence techniques. This study will support future research on taxonomic identification and diagnosis of both modern and archaeological capillariids.

Keywords: Taxonomy, Artificial intelligence, Species identification, Capillaridae, Parasite eggs

*Correspondence: alenainiguez@gmail.com

${ }^{1}$ Laboratório de Biologia de Tripanosomatídeos-LABTRIP, Instituto Oswaldo Cruz, IOC-FIOCRUZ, Rio de Janeiro, RJ, Brazil

Full list of author information is available at the end of the article

\section{Background}

There are more than 300 species of capillariids that parasitize various vertebrate groups (fish, amphibians, reptiles, avian and mammals) worldwide [1]. Species 
identification is hindered because of the few taxonomically informative structures available, making the task laborious and the genus or species definition controversial. Consequently, its taxonomy is one of the most complex among Nematoda, which makes the identification at the genus or species level difficult.

Moravec (1982) proposed a new taxonomy classification for capillariids to serve as a foundation for future studies, thus raising the genera to family Capillaridae Neveu-Lemaire, 1936 (Nematoda: Trichocephalida), because of the difference in worm morphologies, the variety of infection sites and their definitive hosts. The taxonomy of the genera was based mainly on morphological characteristics of the posterior termination of males. Therefore, dividing the capillariids into 16 genera (12 redefined, 2 rescued and 2 created) was suggested [1].

The suggested genera were: Schulmanela Ivashkin, 1964, Paracapillaria Mendonça, 1963, Capillostrongyloides Freitas and Lent, 1935; Pseudocapillaria Freitas, 1959; Liniscus Dujardin, 1845; Pearsonema Freitas and Mendonça, 1960; Echinocoleus López-Neyra, 1947; Capillaria Zeder, 1800; Eucoleus Dujardin, 1845; Pterothominx Freitas, 1959; Aonchotheca López-Neyra, 1947; Calodium Dujardin, 1845; Gessyella Freitas, 1959; Skrjabinokillaria Skarbilovich, 1946. Additionally, two new genera were described, Freitascapillaria gen. n. and Baruscapillaria gen. n. [1]. Subsequently, other genera were added to the family, totaling 22 genera. These are: Pseudocapillaroides Moravec and Cosgrove, 1982; Piscicapillaria Moravec, 1982; Amphibiocapillaria Moravec, 1982; Tenoranema Mas-Coma and Esteban, 1985; Paratrichosoma Ashford and Muller, 1978 [2].

In 2010, Gibbons expanded the classification proposing other genera in the subfamily Capillarinae. Some of the genera that were classified in this subfamily are: Tridentocapillaria Barus and Sergeeva, 1990; Brevithominx Teixeira de Freitas and Machado de Mendonça, 1964; Paracapillaroides Moravec, Salgado-Maldonado and Caspeta-Mandujano, 1999; Crocodylocapillaria Moravec and Spratt, 1998 [3]. Although scarce, some molecular studies were performed to support the systematic classification of the group and confirmed the classification of the genera proposed by Moravec (1982) [4-6].

Eggs are the parasitic structures most viewed in coprological analysis, both in modern samples, from public health or ecological surveys, and in ancient samples, from paleoparasitological studies [7]. Most of the eggs detected in ancient samples are not identified at the genus or species level, and in modern samples, when just eggs are detected, the identification is impaired [6]. Although species and genera of capillariids are identified primarily based on the structure of the posterior end of male adults, the structure of the egg could also play a role in genera or species discrimination $[1,8]$.

Artificial intelligence (AI) is described as the ability of a machine to perform "intelligent" functions, for instance, learning, decision-making, adaptation, control and perception [9]. To execute such functions, a classification process must be triggered so that scenarios can be identified, grouped and properly treated. Machine learning (ML) is a useful AI approach when this classification process depends on a huge data analysis. ML has been used for epidemiological research [10], diagnosis [11], discriminating pathogens [12] and for resolving taxonomic relationships with molecular data [13]. Thus, we propose that the complexity of Capillariidae species definition, based on egg structures, could be clarified using AI tools. A taxonomic dataset including morphological and morphometrical characteristics of parasite eggs and ecological information was constructed based on specimens from institutional helminth collections. Institutional biological collections are taxonomic respositories of specimens described and strictly identified by experienced taxonomists. The current research proposed a novel procedure for taxonomic species identification, integrating data from centenary biological collections and the logic of artificial intelligence approaches.

\section{Materials and methods}

\section{Morphological and morphometric analyses}

The specimens were collected from two institutional helminth collections: the Coleção Helmintológica do Instituto Oswaldo Cruz (CHIOC) from Fundação Oswaldo Cruz (FIOCRUZ), Brazil, 14 species (20 specimens), and the Collection de Nématodes Zooparasites du Muséum National d'Histoire Naturelle de Paris (MNHN), France, 16 species (17 specimens).

The eggs were separated from the specimens for morphological and morphometric analyses. Females containing eggs were collected to separate eggs or fragments containing eggs when it was not possible to manually extract them from inside the females. Eggs were extracted from the final portion of the uterus. For clear visualization of egg morphometry, samples were subjected to an ultrasonic bath (Cristófoli ${ }^{\circledR}$ ) for $60 \mathrm{~s}$ at the frequency of $42 \mathrm{hHz}$. The process was done to clean dirt and fragments from females, so that only eggs with the chitin shell were present.

The eggs' morphology and morphometry were characterized by an optical microscope (Nikon Eclipse E200) at $400 \times$ magnification using image analysis software (Image Pro Plus-Media Cybernetics, USA). Thirty eggs per specimen were evaluated, whenever available. The measures considered were: total diameter (width) and length of the eggs, mean value of the width and height of the 


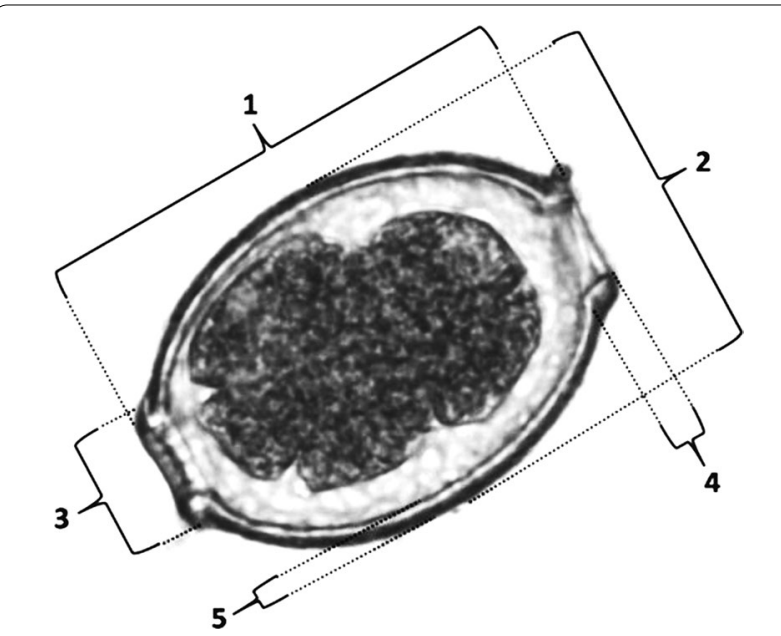

Fig. 1 Representation of capillariid egg measurements considered in the present study based on Baruscapillaria obsignata voucher CHIOC26715. The five measures taken were: 1 : total length; 2 : total width; 3 : base of the polar plug width; 4 : base of the polar plug height; 5 : shell thickness

two plugs and the thickness of the shell (Fig. 1). A qualification of the ornaments presented in the outer bark of capillariid eggs was also performed. The parameter of egg ornamentation was divided in four categories following the literature [14]: (1) smooth, which has no ornaments on the shell, as described by Conboy for Trichuris trichiura eggs [15]; (2) punctuated, which has dots like a pitted surface, as described in Eucoleus bohemi by Conboy and Traversa et al. [15, 16]; (3) reticulated type I (RTI), which presents like a network of interconnected ridges as described in Eucoleus aerophilus by Conboy [15]; (4) reticulated type II (RTII), which presents like a network but with an orientation of deep longitudinal ridges, as described in Aonchotheca putorii by Zajac and Conboy [17] (Fig. 2a-d).

\section{Discriminant analyses and artificial intelligence/machine learning approaches}

A dataset of capillariid species from FIOCRUZ and MNHN collections was constructed with the morphological (eggshell ornamentation) and morphometric parameters (MM) (total length and width, base of the polar plug width and height and shell thickness) generated by specimens. In addition, ecological parameters, such as information about the host $(\mathrm{H})$ and geographical location (GL) of specimens, were included. A total of 997 entries were generated (Additional file 1: Table S1).

Discriminant analyses were performed using Past 3.16 software to separate species groups. First, the total length and width of eggs from all species were plotted; then, the discriminant function analysis was generated by each eggshell ornamentation: punctual, RTI and RTII. The exception was smooth ornamentation with only one species identified.

For ML/AI analyses, ornamentation and ecological parameters were encoded into numerical variables. Ecological parameters were defined as host (fish, amphibian, reptile, avian, mammal) and as geographical location (South America, Central America, North America, Europe, Africa, Asia, Oceania). Response variables were $1=$ yes or presence; $0=$ no or absence; $-1=$ no information available. To evaluate the more reliable set of sample information to lead to an identification, MM parameters were tested alone and in combination with ecological parameters, $\mathrm{MM}+\mathrm{H}, \mathrm{MM}+\mathrm{GL}$ and $\mathrm{MM}+\mathrm{H}+\mathrm{GL}$.

Since no literature on ML algorithms is applied to taxonomic species definition, an exhaustive test of several algorithms available on Weka 3.8.3 software [18] was conducted. In addition, the present research looked for new criteria to find, describe and name particular species, while keeping the top-down approach of a taxonomy rank. There are several ML/AI algorithms for classification, but only some of them provide decision trees which are similar to the taxonomic keys proposed/ used by systematics specialists to discriminate biological species. Therefore, we focused on Weka's algorithms, which returned representations of decision trees, namely: J48 [19], Random Tree [20], REPTree [21] and Logistic Model Tree (LMT) [22]. The ML classification algorithms produced training models that were tested using cross-validation, providing kappa values. Moreover, we implemented an additional classification using a Majority Voting algorithm [23], which integrates all four decision tree classifiers to combine the predictions from multiple ML algorithms and to exploit the different peculiarities of each algorithm. The performance of five algorithms was reported as metrics of sensitivity, specificity, negative predictive value (NPV), positive predictive value (PPV) and accuracy [24] in addition to the correct instances percentage, kappa coefficient and area under the receiver-operating characteristic (ROC) curve (AUC), as informed by Weka.

Statistical analysis was applied to check the null hypothesis for equal proportions of the AUC values among the algorithms-J48, Random Tree, REPTree, Logistic Model Tree and Majority Voting (H0 $\mathrm{p} 1=\mathrm{p} 2=\mathrm{p} 3=\mathrm{p} 4=\mathrm{p} 5)$ - and among parameters$\mathrm{MM}+\mathrm{H}+\mathrm{GL}, \mathrm{MM}+\mathrm{H}, \mathrm{MM}+\mathrm{GL}$ and $\mathrm{MM}+\mathrm{H}+\mathrm{GL}$ $(\mathrm{H} 0 \mathrm{p} 1=\mathrm{p} 2=\mathrm{p} 3=\mathrm{p} 4)$. To arrive at a conclusion about the hypothesis with $95 \%$ confidence, the $P$-value of the chi-square statistic should be $<0.05$, indicating that the difference is significant, and $<0.01$ for highly significant. Subsequently, the Marascuilo procedure was applied 
to check which proportions were different among the algorithms and among the combinations of parameters applied. Data analyses were performed using RStudio version 3.5.1 (2018-07-02) software.

\section{Results}

\section{Morphological and morphometric analyses}

The species of Capillariidae studied here, in general, presented a barrel shape, varying between round and elongated, with polar plugs, and the eggshell usually had ornamentation, as described in the literature [25]. A total of 28 species of capillariids distributed in eight genera were characterized. Regarding eggshell ornaments, they were classified as smooth $(n=1)$, punctuated $(n=10)$, RTI $(n=7)$ and RTII $(n=10)$ (Figs. 3, 4, 5; Table 1) ( $n=$ number of species classified in each ornamentation).

In all genera with more than one species to compare, a high heterogeneity of measurements was observed: an amplitude of 37.06-70.39 $\mu \mathrm{m}$ for length, $18.15-34.40 \mu \mathrm{m}$ for width, 5.43-12.95 $\mu \mathrm{m}$ for plug base width, 1.09$5.68 \mu \mathrm{m}$ for plug base height and 0.78-5.57 $\mu \mathrm{m}$ for eggshell thickness (Table 1; Additional file 1: Table S1).

\section{Genus Aonchotheca}

Five species were collected from Collection de Nématodes Zooparasites of MNHN. The hosts of all the species were registered as mammals: Aonchotheca annulosa in Apodemus sylvaticus; A. baylisi in Lophuromys sikapusi; A. erinaceid in Erinaceus europaeus; A. murissylvatici in Evotomys glareolus; A. myoxinitelae in Eliomys quercinus; A. pulchra in Tadarida laticaudata and Nyctinomus brasiliensis. In general, the egg morphology was very similar, and the plug bases were mostly prominent, except in $A$. baylisi, which had a thickening of the eggshell in the plug base region, masking the prominence. The most common egg ornamentation was RTII with four species (Fig. 5l, n, $\mathrm{p}, \mathrm{r})$. One punctuated type ornamentation was present (Fig. 5t). Aonchotheca pulchra was the only species in this study that did not have ornamentation on the eggshell surface (Fig. 5f). Aonchotheca baylisi had the smallest egg in the genus $(44.75-50.14 \times 24.92-28.97 \mu \mathrm{m})$, in contrast with $A$. myoxinitelae $(55.44-61.57 \times 24.77-26.76 \mu \mathrm{m})$.

\section{Genus Baruscapillaria}

A total of five species were collected from the collections of MNHN and FIOCRUZ. The hosts of all the species were registered as avian: Baruscapillaria obsignata in Gallus gallus domesticus; B. rudolphi in Tinamus solitarius; B. spiculata in Carbo vigua; B. falconis in Tyto alba; B. resecta in Garrulus glandariu. RTI (Fig. 5f, r) and II (Fig. 5b, n) were observed in two species, each type, and one punctuated (Fig. 5j). The eggs were very similar within the genus in shape and in plug base morphology. Baruscapillaria resecta was the species with the biggest egg measurements $(65.47-70.39 \times 29.58-31.81 \mu \mathrm{m})$.

\section{Genus Capillaria}

Four species were collected from both MNHN and FIOCRUZ. The hosts were registered as avian and mammal: Capillaria venusta in Ramphasto toco; C. collaris in Gallus gallus domesticus; C. brasiliana in Nycticorax naevius; C. exigua in Erinaceus europaeus. The morphologies of the eggs were very different in shape. The genus showed the three different types of ornamentations (RTI, RTII and punctuated).
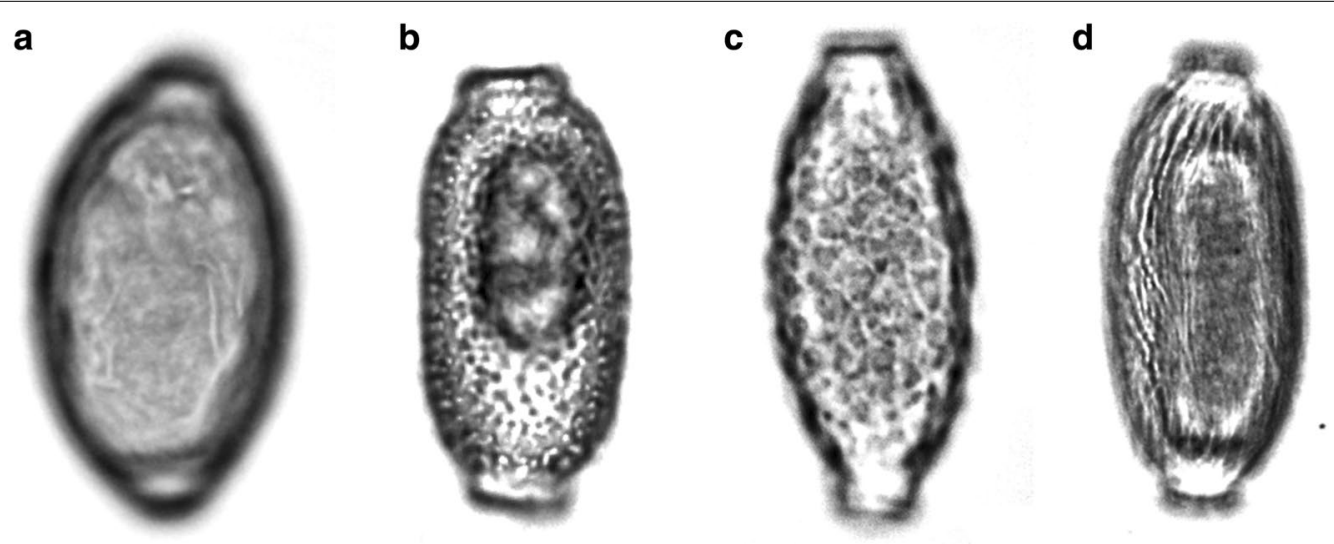

Fig. 2 Representation of each ornamentation pattern considered in the present study based on capillariid eggs from CHIOC species. a Smooth from Aonchotheca pulchra voucher CHIOC9804; b punctuated from Capillaria brasiliana voucher CHIOC7046; c reticulated type I from Pearsonema plica voucher MNHN373; d reticulated type II from Baruscapillaria resecta voucher MNHN1073. Representations are based on images that are intentionally blurry on the general plane to focus on the ornamentation plane 


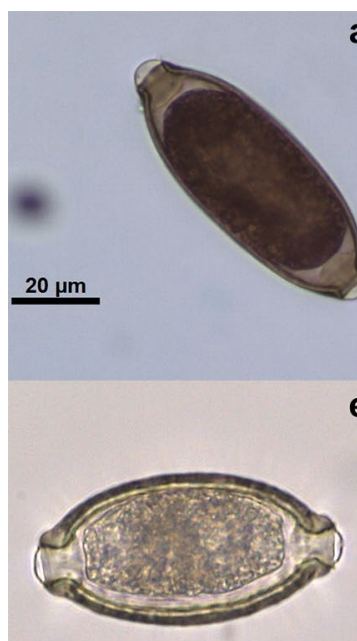

a

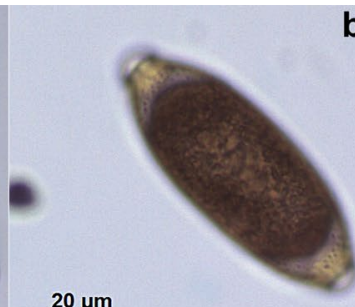

e $20 \mu \mathrm{m}$

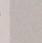

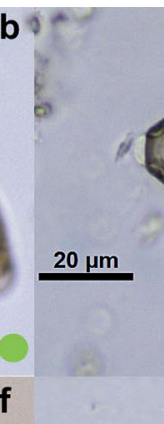

f

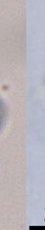

$20 \mu \mathrm{m}$

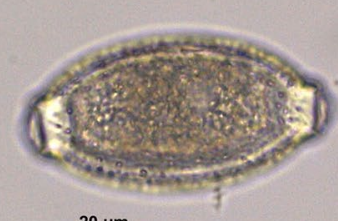

$20 \mu \mathrm{m}$

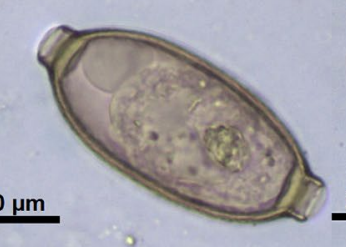

g

h

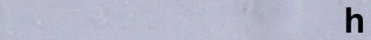

j

k
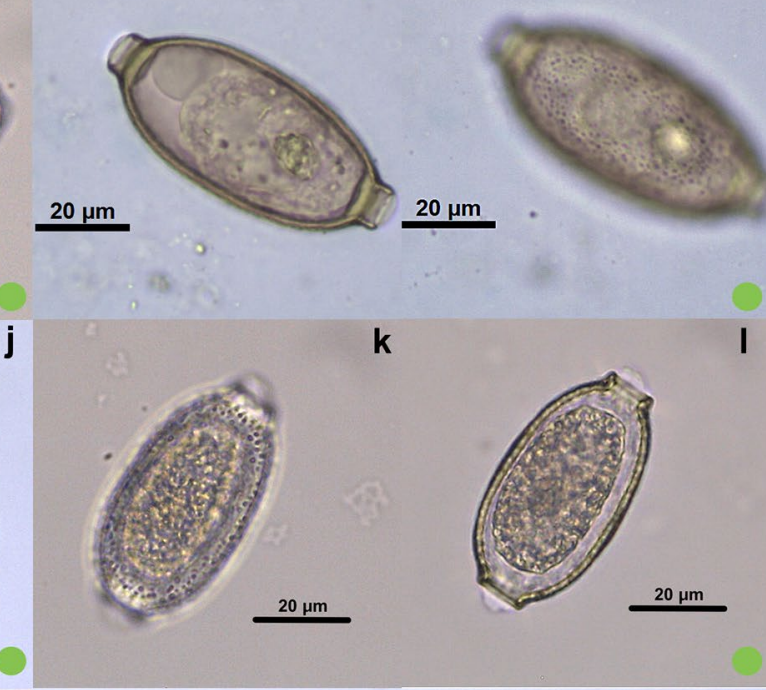

I

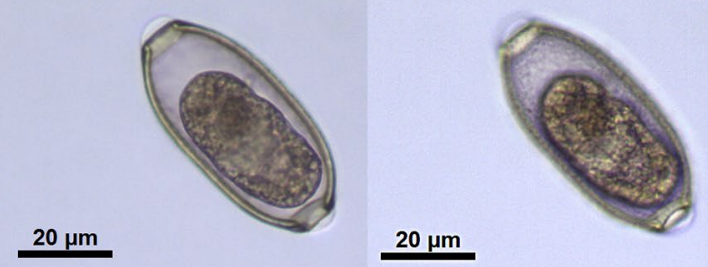

m

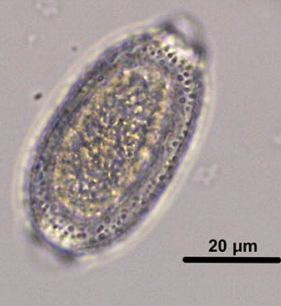

n

p
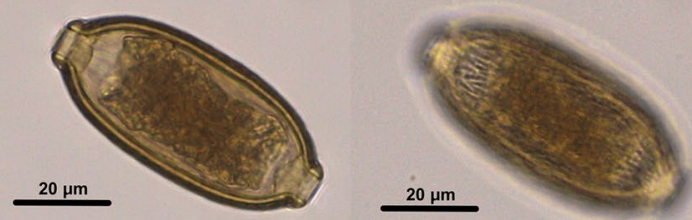

$20 \mu \mathrm{m}$
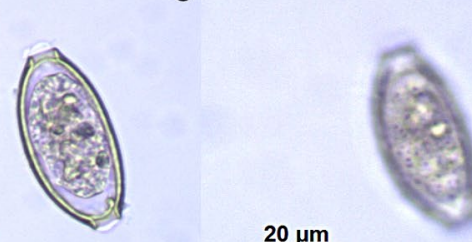

$20 \mu \mathrm{m}$

Fig. 3 Micrographies of Eucoleus genus eggs. The first image $(\mathbf{a}, \mathbf{c}, \mathbf{e}, \mathbf{g}, \mathbf{i}, \mathbf{k}, \mathbf{m}, \mathbf{o})$ of each species is an egg overview, and the second image (b $\mathbf{d}, \mathbf{f}, \mathbf{h}, \mathbf{j}, \mathbf{l}, \mathbf{n}, \mathbf{p})$ focuses on ornamentation. a, b Eucoleus anullatus; $\mathbf{c}, \mathbf{d}$ E. dubius; $\mathbf{e}, \mathbf{f}$ E. bacilatus; $\mathbf{g}, \mathbf{h}$ E. eberthi; $\mathbf{i}, \mathbf{j}$ E. contortu; $\mathbf{k}, \mathbf{I}$ E. madjerdae; $\mathbf{m}$, $\mathbf{n}$ E. dispar; $\mathbf{0}, \mathbf{p}$ E. perforans. Each colored dot represents an ornamentation pattern: green dot: punctuated; blue dot: reticulated type I; red dot: reticulated type II. Images intentionally focus on the ornamentation plane

\section{Genus Calodium}

Only one species was collected from Collection de Nématodes Zooparasites of MNHN. The hosts were recorded as mammals: Calodium hepaticum in Meriones persicus and Rattus rattus. This species has a very peculiar morphology. The ornamentation is punctuated and, in a transversal view, a radial ornamentation is observed on the eggshell. The thickest eggshell was detected in this species $(5.54 \mu \mathrm{m})$.

\section{Genus Echinocoleus}

Two species were collected from the helminth collection of CHIOC/FIOCRUZ. The hosts registered were mammals: Echinocoleus hydrochoeris in Hydrochoerus capybara; Ec. auritae in Metachirops opossum. The ornaments identified were punctuated (Fig. 4d) and RTI (Fig. 4b), respectively. Both had a very thick eggshell $(2.1-3.51 \mu \mathrm{m}$ and $1.59-3.63 \mu \mathrm{m}$, respectively). Echinocoleus auritae has a particular eggshell ornament, with a prominent reticulated suface in the transversal view. 


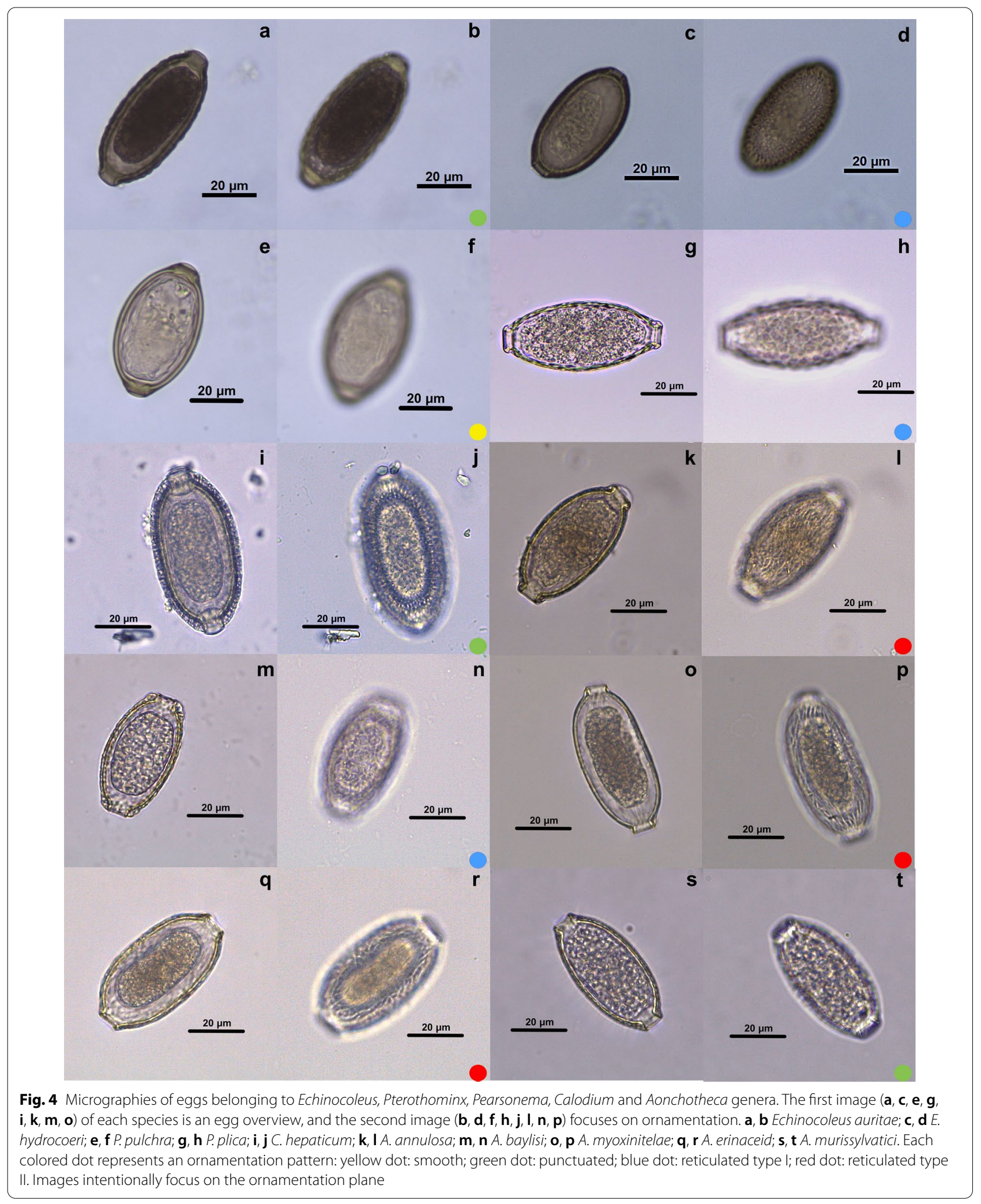




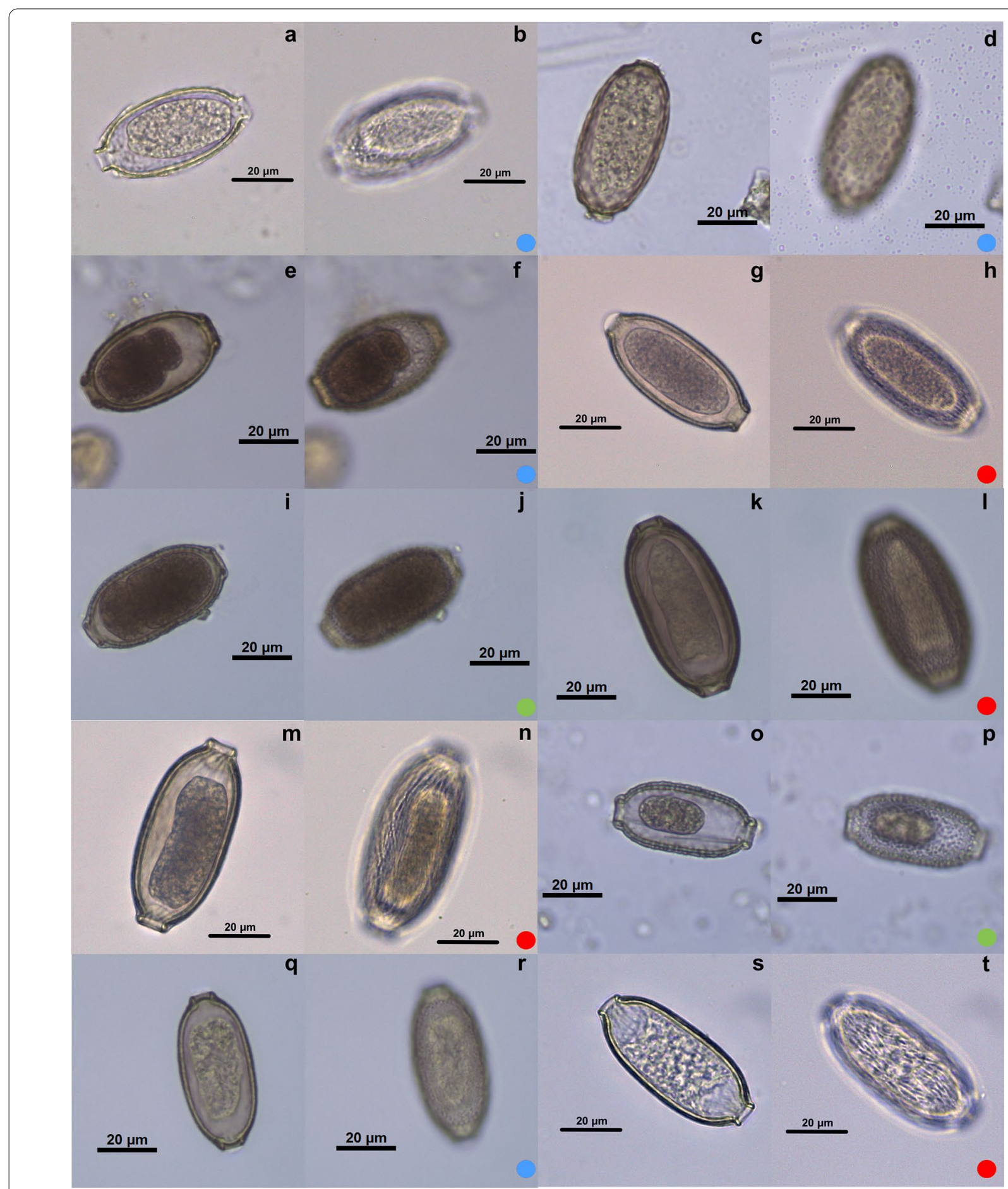

Fig. 5 Micrographies of eggs belonging to Baruscapillaria, Capillaria and Tridentocapillaria genera. The first image $(\mathbf{a}, \mathbf{c}, \mathbf{e}, \mathbf{g}, \mathbf{i}, \mathbf{k}, \mathbf{m}, \mathbf{o})$ of each species is an egg overview, and the second image $(\mathbf{b}, \mathbf{d}, \mathbf{f}, \mathbf{h}, \mathbf{j}, \mathbf{l}, \mathbf{n}, \mathbf{p})$ focuses on ornamentation. $\mathbf{a}, \mathbf{b}$ Baruscapillaria falconis; $\mathbf{c}, \mathbf{d}$ Capillaria collaris; $\mathbf{e}$, $\mathbf{f}$ B. obsignata; $\mathbf{g}, \mathbf{h}$ C. exigua; $\mathbf{i}, \mathbf{j}$ B. spiculata; $\mathbf{k}, \mathbf{I}$ C. venusta; $\mathbf{m}, \mathbf{n}$ B. resecta; $\mathbf{o}, \mathbf{p}$ C. brasiliana; $\mathbf{q}, \mathbf{r}$ B. rudolphi; $\mathbf{s}, \mathbf{t}$ Tridentocapillaria tridens. Each colored dot represents an ornamentation pattern: green dot: punctuated; blue dot: reticulated type l; red dot: reticulated type II. Images intentionally focus on the ornamentation plane 
Table 1 Morphometry of Capillariidae species with measurements of length, width, plug width, plug thickness and shell thickness

\begin{tabular}{|c|c|c|c|c|c|c|c|c|c|c|c|}
\hline \multirow[t]{2}{*}{ Species } & \multicolumn{2}{|c|}{ Length $(\mu \mathrm{m})$} & \multicolumn{2}{|c|}{ Width $(\mu \mathrm{m})$} & \multicolumn{2}{|c|}{ Plug base W $(\mu \mathrm{m})$} & \multicolumn{2}{|c|}{ Plug base $\mathrm{H}(\mu \mathrm{m})$} & \multicolumn{2}{|c|}{ Shell $(\mu \mathrm{m})$} & \multirow{2}{*}{$\begin{array}{l}\text { Shell } \\
\text { ornamentation }\end{array}$} \\
\hline & Mean & Amplitude & Mean & Amplitude & Mean & Amplitude & Mean & Amplitude & Mean & Amplitude & \\
\hline Aonchotheca annulosa & 53.11 & $49.28-55.96$ & 28.04 & $26.03-32.60$ & 8.91 & $7.23-10.28$ & 3.50 & $2.52-4.58$ & 2.66 & $1.98-3.36$ & 4 \\
\hline Aonchotheca baylisi & 46.56 & $44.75-50.14$ & 26.50 & $24.92-28.97$ & 7.75 & $6.40-9.28$ & 3.85 & $2.69-5.27$ & 2.66 & $1.78-3.48$ & 4 \\
\hline Aonchotheca erinacei & 54.81 & $52.67-57.37$ & 30.98 & $27.99-33.70$ & 9.66 & $7.99-12.26$ & 3.00 & $1.83-4.04$ & 2.50 & $1.64-3.09$ & 4 \\
\hline Aonchotheca murissylvatici & 53.10 & $50.75-55.70$ & 26.17 & $24.91-27.82$ & 8.43 & $7.33-9.74$ & 3.74 & $2.75-4.83$ & 2.80 & $2.29-3.42$ & 2 \\
\hline Aonchotheca myoxinitelae & 57.74 & $55.44-61.57$ & 25.83 & $24.77-26.76$ & 8.25 & $6.83-9.24$ & 3.21 & $2.47-4.06$ & 1.68 & $1.34-2.11$ & 4 \\
\hline Aonchotheca pulchra & 49.52 & $46.15-52.96$ & 30.89 & $28.15-34.40$ & 8.52 & $7.42-9.38$ & 4.09 & $2.77-5.68$ & 1.82 & $1.41-2.32$ & 1 \\
\hline Baruscapillaria obsignata & 47.46 & $42.17-51.78$ & 27.94 & $24.76-33.45$ & 9.97 & $7.13-12.94$ & 2.84 & $1.09-4.62$ & 1.77 & $1.18-2.52$ & 3 \\
\hline Baruscapillaria rudo/phi & 54.34 & $52.57-57.56$ & 24.84 & $22.88-26.84$ & 8.33 & $6.74-9.37$ & 4.01 & $3.34-4.85$ & 2.18 & $1.78-2.61$ & 3 \\
\hline Baruscapillaria spiculata & 53.17 & $51.48-55.69$ & 27.02 & $24.11-30.47$ & 1.85 & $9.17-12.01$ & 2.67 & $1.98-3.61$ & 2.38 & $1.88-2.79$ & 2 \\
\hline Baruscapillaria falconis & 54.30 & $52.54-55.85$ & 26.23 & $25.28-28.19$ & 7.95 & $6.92-8.68$ & 3.32 & $2.51-4.06$ & 1.51 & $1.00-2.54$ & 4 \\
\hline Baruscapillaria resecta & 68.12 & $65.47-70.39$ & 30.53 & $29.58-31.81$ & 9.56 & $8.37-10.79$ & 3.88 & $2.87-5.07$ & 2.73 & $1.85-3.43$ & 4 \\
\hline Capillaria venusta & 60.21 & $54.01-63.29$ & 30.00 & $21.95-32.27$ & 9.95 & $8.56-11.65$ & 3.60 & $2.54-4.60$ & 2.83 & $1.45-3.98$ & 4 \\
\hline Capillaria colaris & 52.33 & $46.91-56.82$ & 26.46 & $23.81-30.03$ & 8.32 & $7.24-9.04$ & 3.36 & $2.20-4.64$ & 1.46 & $0.84-2.22$ & 3 \\
\hline Capillaria brasiliana & 46.45 & $43.10-50.24$ & 21.41 & $19.06-22.88$ & 8.80 & $7.23-10.66$ & 2.67 & $1.66-3.6$ & 2.05 & $1.63-2.86$ & 2 \\
\hline Capillaria exigua & 55.10 & $52.73-56.73$ & 26.33 & $25.18-27.12$ & 8.06 & $7.13-9.08$ & 2.84 & $1.94-3.59$ & 1.61 & $1.31-1.98$ & 4 \\
\hline Calodium hepaticum & 55.44 & $50.07-62.02$ & 30.42 & $27.38-33.84$ & 8.08 & $7.07-9.86$ & 4.24 & $3.16-5.18$ & 4.34 & $3.26-5.57$ & 2 \\
\hline Echinocholeus hydrochoeri & 49.34 & $46.18-51.74$ & 25.14 & $22.43-27.62$ & 6.72 & $5.92-7.91$ & 3.78 & $2.58-5.00$ & 2.65 & $1.59-3.63$ & 2 \\
\hline Echinocholeus auritae & 57.69 & $56.13-59.84$ & 26.13 & $24.71-27.82$ & 7.74 & $6.85-8.80$ & 4.84 & $3.99-6.15$ & 2.72 & $2.1-3.51$ & 3 \\
\hline Eucoleus perforans & 39.86 & $37.06-42.81$ & 20.41 & $18.15-23.94$ & 6.37 & $5.43-7.45$ & 2.50 & $2.05-3.38$ & 1.57 & $1.08-2.24$ & 2 \\
\hline Eucoleus annulatus & 65.36 & $61.45-68.78$ & 26.75 & $24.87-27.71$ & 8.56 & $6.24-10.22$ & 3.33 & $2.47-5.33$ & 1.13 & $0.78-1.63$ & 2 \\
\hline Eucoleus contortus & 51.07 & $46.70-54.07$ & 26.24 & $24.49-28.21$ & 8.03 & $6.71-9.62$ & 2.36 & $1.59-3.77$ & 1.42 & $1.08-1.82$ & 2 \\
\hline Eucoleus dubius & 52.14 & $47.07-55.25$ & 23.62 & $22.40-25.57$ & 8.82 & $7.73-9.80$ & 3.43 & $2.44-4.24$ & 2.28 & $1.76-2.73$ & 3 \\
\hline Eucoleus eberthi & 65.89 & $63.15-69.82$ & 29.27 & $28.55-29.86$ & 9.59 & $8.53-10.55$ & 5.30 & $4.23-7.01$ & 1.59 & $1.25-1.97$ & 2 \\
\hline Eucoleus bacilatus & 63.09 & $60.53-68.29$ & 32.78 & $32.04-33.65$ & 11.24 & $9.70-12.95$ & 4.78 & $3.86-6.05$ & 3.97 & $3.17-4.63$ & 2 \\
\hline Eucoleus madjerdae & 53.41 & $51.81-55.10$ & 29.23 & $28.41-29.99$ & 10.38 & $8.82-11.19$ & 3.29 & $2.16-4.53$ & 2.13 & $1.53-2.53$ & 2 \\
\hline Eucoleus dispar & 63.42 & $60.34-68.39$ & 29.65 & $28.19-32.81$ & 8.89 & $7.63-10.93$ & 3.94 & $2.79-5.40$ & 2.90 & $2.34-3.68$ & 4 \\
\hline Pearsonema plica & 62.62 & $60.30-65.32$ & 27.47 & $26.35-28.76$ & 9.62 & $8.48-10.87$ & 4.47 & $3.40-5.28$ & 2.24 & $1.71-2.55$ & 3 \\
\hline Tridentocapillaria tridens & 60.60 & $57.39-63.33$ & 27.54 & $25.84-29.81$ & 8.34 & $7.04-9.23$ & 2.84 & $1.99-4.22$ & 2.86 & $2.49-3.13$ & 4 \\
\hline
\end{tabular}

Shell ornamentations: 1 , smooth; 2 , punctuated; 3 , reticulated type I; 4 , reticulated type II

\section{Genus Eucoleus}

Four species were collected from both collections. The hosts were avian and mammal: Eucoleus perforans in Numida meleagris; E. annulatus in Gallus gallus domesticus; E. contortus in Sterna maxima and Ajaja ajaja; E. dubius in Attila cinereus; E. eberthi in Metachirops opossum; E. bacilatus in Apodemus sylvaticus; E. madjerdae in Mus musculus; E. dispar in Atlapetes semirufus. Most eggs observed in the genus Eucoleus had the punctuated ornamentation (Fig. 3b, f, h, j, l, p), but one species had RTI and another species presented RTII. Eucoleus genus showed the most variable measurements of length $(37.06-68.82 \mu \mathrm{m})$ and width $(18.15-33.65 \mu \mathrm{m})$ among its species. The same was observed on plug base measurements, plug base length and width, and on eggshell thickness. The smallest of all capillariid species is E. perforans $(37.06 \times 18.91 \mu \mathrm{m})$, and the thinnest is $E$. annulatus $(0.78 \mu \mathrm{m})$.

\section{Genus Pearsonema}

Only one species was collected from Collection de Nématodes Zooparasites of MNHN. The host was registered as a mammal: Pearsonema pulchra in Vulpes vulpes. The egg had a very elongated morphology, with a prominent RTI eggshell.

\section{Genus Tridentocapillaria}

Only one species was collected from the Collection de Nématodes Zooparasites of MNHN. The host was registered as avian: Tridentocapillaria tridens in Cyanolanius madagascarinus. The species T. tridens had RTII ornamentation.

\section{Discriminant analyses and artificial intelligence/machine learning approaches}

The graphic XY of length and width measures for all species revealed a strong superposition of data with a more 


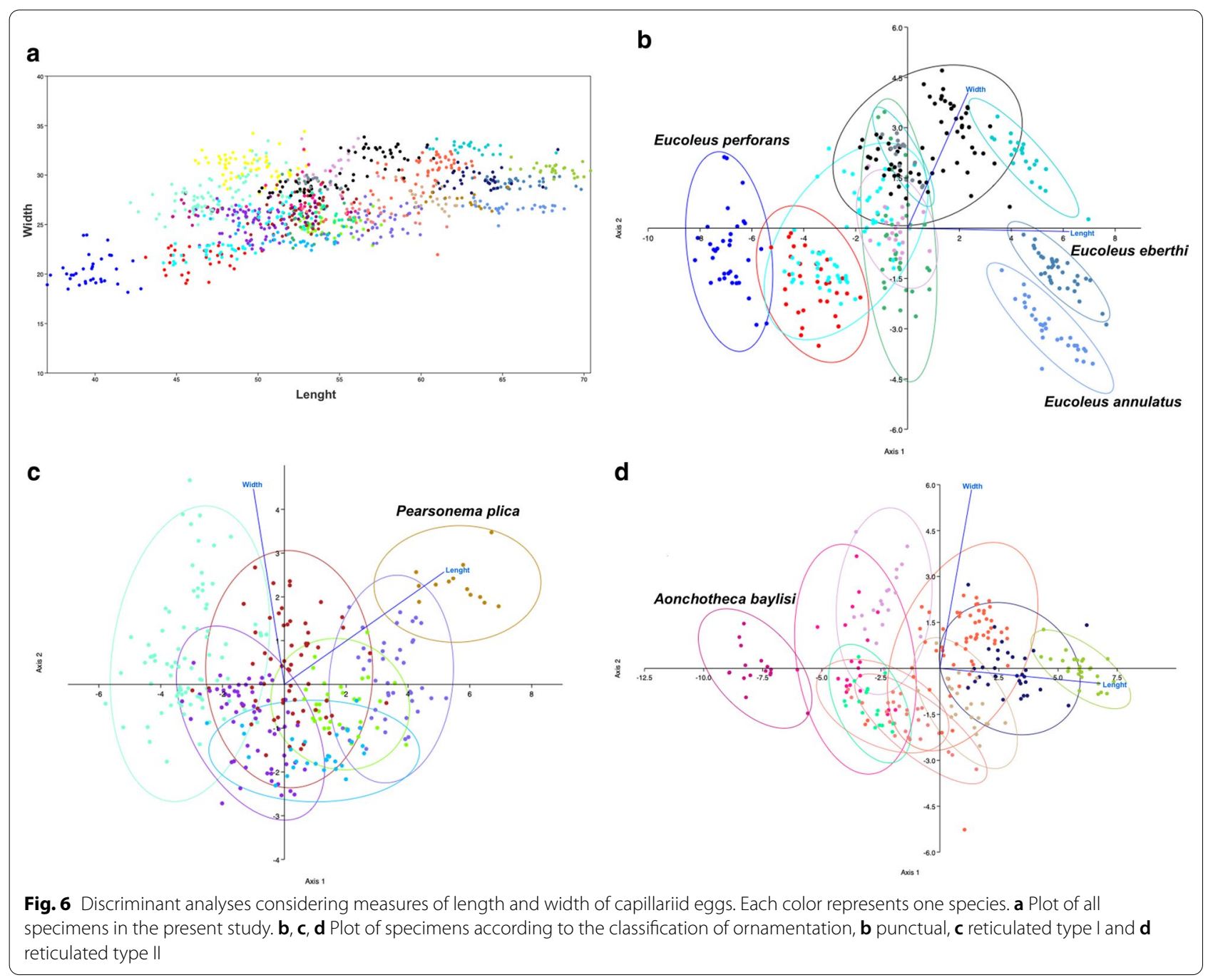

discriminant distribution in the egg length than egg width parameter (Fig. 6a). The graphics of discriminant analysis by eggshell ornamentation showed the same pattern of species overlapping, with only one to three species groups showing adequate parameters for capillariid identification (Fig. 6b-d), with the discrimination of $E$. perforans, E. annulatus, E. eberthi (Punctuated) (Fig. 6b), P. plica (RTII) (Fig. 6c) and A. baylisi (RTII) (Fig. 6d).

The LMT algorithm showed the highest values in all metrics compared with the other algorithms (Table 2). However, the LMT algorithm does not return representations of traditional decision trees that could be representative of a taxonomic classification. The Majority Voting algorithm showed high metric values, but the combined classifiers did not attenuate the errors revealed in each algorithm alone (Table 2; Additional file 1: Tables S2, S3). From all the algorithms that produced representative decision trees, J48 showed higher values in all metrics, with the exception of AUC (0.979), which was higher for
REPTree (0.986) in all parameter combinations (Table 2). The performance of algorithms using morphological and morphometric data without ecological parameters (MM) revealed the worst metrics (Table 2).

The statistical test showed a highly significant difference among the algorithms $(P<0.001)$ and among the parameters $(P<0.001)$, thus rejecting the null hypothesis of equal proportions (Additional file 1: Tables S2). The Marascuilo results between the combination of parameters showed statistical differences when no ecological parameters were applied (MM), using all the algorithms, except in RandomTree and Majority Voting. Comparing algorithms, a significant difference is observed when the LMT is applied for all the parameters, except for the MM parameter compared with Majority Voting (Additional file 1: Tables S2). In general, there was no statistical significance when comparing the Majority Voting algorithm with each algorithm that produced representative decision trees (J48, RandomTree and 
Table 2 Algorithms and parameters considered in the ML/IA analysis

\begin{tabular}{|c|c|c|c|c|c|c|c|c|}
\hline \multirow[t]{2}{*}{ Algorithms } & \multicolumn{8}{|l|}{$M M+G L+H$} \\
\hline & $\begin{array}{l}\text { Correct instances } \\
(\%)\end{array}$ & Kappa & Specificity & Sensitivity & AUC & Accuracy & NPV & PPV \\
\hline$J 48$ & 93.172 & 0.92 & 0.962 & 0.966 & 0.979 & 0.964 & 0.965 & 0.964 \\
\hline Random Tree & 89.257 & 0.89 & 0.934 & 0.951 & 0.944 & 0.942 & 0.949 & 0.936 \\
\hline REPTree & 90.963 & 0.90 & 0.959 & 0.945 & 0.986 & 0.952 & 0.943 & 0.961 \\
\hline LMT & 96.385 & 0.96 & 0.981 & 0.982 & 0.999 & 0.981 & 0.981 & 0.982 \\
\hline Majority Voting & 94.679 & 0.94 & 0.974 & 0.970 & 0.972 & 0.964 & 0.969 & 0.975 \\
\hline \multirow[t]{2}{*}{ Algorithms } & \multicolumn{8}{|l|}{$\mathrm{MM}+\mathrm{H}$} \\
\hline & $\begin{array}{l}\text { Correct instances } \\
(\%)\end{array}$ & Kappa & Specificity & Sensitivity & AUC & Accuracy & NPV & PPV \\
\hline$J 48$ & 88.253 & 0.88 & 0.932 & 0.941 & 0.955 & 0.937 & 0.939 & 0.934 \\
\hline Random Tree & 86.646 & 0.86 & 0.949 & 0.935 & 0.93 & 0.942 & 0.933 & 0.950 \\
\hline REPTree & 85.943 & 0.85 & 0.919 & 0.911 & 0.979 & 0.915 & 0.908 & 0.921 \\
\hline LMT & 93.975 & 0.94 & 0.965 & 0.972 & 0.998 & 0.968 & 0.971 & 0.966 \\
\hline Majority Voting & 91.867 & 0.91 & 0.955 & 0.959 & 0.957 & 0.957 & 0.958 & 0.956 \\
\hline \multirow[t]{2}{*}{ Algorithms } & \multicolumn{8}{|l|}{$\mathrm{MM}+\mathrm{GL}$} \\
\hline & $\begin{array}{l}\text { Correct instances } \\
(\%)\end{array}$ & Kappa & Specificity & Sensitivity & $A \cup C$ & Accuracy & NPV & PPV \\
\hline$J 48$ & 92.570 & 0.92 & 0.960 & 0.961 & 0.975 & 0.961 & 0.960 & 0.961 \\
\hline Random Tree & 91.566 & 0.91 & 0.951 & 0.959 & 0.956 & 0.955 & 0.958 & 0.953 \\
\hline REPTree & 89.056 & 0.88 & 0.942 & 0.941 & 0.98 & 0.941 & 0.939 & 0.944 \\
\hline LMT & 96.686 & 0.96 & 0.984 & 0.982 & 0.999 & 0.983 & 0.981 & 0.985 \\
\hline Majority Voting & 95.683 & 0.95 & 0.980 & 0.975 & 0.978 & 0.978 & 0.975 & 0.980 \\
\hline \multirow[t]{2}{*}{ Algorithms } & \multicolumn{8}{|l|}{ MM } \\
\hline & $\begin{array}{l}\text { Correct instances } \\
(\%)\end{array}$ & Kappa & Specificity & Sensitivity & $A \cup C$ & Accuracy & NPV & PPV \\
\hline$J 48$ & 84.538 & 0.84 & 0.918 & 0.912 & 0.912 & 0.915 & 0.909 & 0.920 \\
\hline Random Tree & 82.228 & 0.81 & 0.885 & 0.917 & 0.917 & 0.901 & 0.915 & 0.888 \\
\hline REPTree & 84.337 & 0.83 & 0.915 & 0.912 & 0.912 & 0.914 & 0.909 & 0.918 \\
\hline LMT & 91.867 & 0.91 & 0.956 & 0.958 & 0.958 & 0.957 & 0.957 & 0.957 \\
\hline Majority Voting & 89.056 & 0.88 & 0.934 & 0.949 & 0.949 & 0.941 & 0.947 & 0.936 \\
\hline
\end{tabular}

Performance of algorithms is reported as specificity, sensitivity and accuracy following [24] and as corrected classified instances, kappa coefficient and AUC, as generated by Weka 3.8.3 software

$M M$ morphological and morphometric data, GL geographical location, $H$ host, $A U C$ area under the receiver-operating characteristic (ROC) curve, NPV negative predictive value, $P P V$ positive predictive value

REPTree). Excluding LMT and Majority Voting (no representative decision trees) and also the MM parameter (lowest AUC values), no statistical significance was seen between REPTree and J48 in all parameter combinations (Additional file 1: Tables S2). We chose the J48 algorithm using all $\mathrm{MM}+\mathrm{H}+\mathrm{GL}$ parameters (higher AUC values) for decision tree representation. However, there was no significant difference when compared with $\mathrm{MM}+\mathrm{GL}$ parameters but there was a difference compared with the $\mathrm{MM}+\mathrm{H}$ parameters.
Figure 7 presents the decision trees generated by the J48 algorithm, applying all ecological parameters and morphological and morphometric data. The decision trees constructed using morphological and morphometric data plus only host $(\mathrm{MM}+\mathrm{H})$ are available in the supporting information (Additional file 2: Fig. S1). The same is found for MM+GL (Additional file 2: Fig. S2) and morphological and morphometric data only (Additional file 2: Figs S3, S4), considering three different ornamentation types, punctuated (Additional file 2: Fig. S3), RTI (Additional file 2: Fig. S4) and RTII 
(Additional file 2: Fig. S5). A classic taxonomic key was made for comparison, using the decision tree generated on AI program Weka 3.8.3 software (Additional file 2: Fig. S6).

\section{Discussion}

Numerous species of capillariids have low host specificity, for instance, Paracapillaria phillipinensis is the only one known to parasitize two different classes of vertebrates, mammals and birds [26]. The difference in natural hosts could imply variability in the shape and/or size of eggs as phenotypical plasticity. This phenomenon occurs when the same species infects different hosts and presents different parasite phenotypes [27], as previously reported in Schistosoma mansoni adult worms. As observed in adult worms, the phenomenon can occur in other development stages, such as eggs.

Initially, to classify capillariids Romashov divided their eggs into six groups, considering only the eggshell surface ornaments and the site of parasite infection. All capillariids analyzed were from mammals, and the author concluded that a relation between those variables is enough to determine the genus, relatively unmistakably [8]. However, in coprological surveys and paleoparasitological studies it is impossible to define the site of infection, because the only datum recorded is the egg itself, sometimes also the host [6,28].

In the present study, the punctuated ornamentation (six species) is predominant in the genus Eucoleus (Table 1). Although E. dispar has a different ornamentation from the other seven species described here, it is similar to E. aerophilus, as seen in the literature [29]. This is supported by molecular phylogenetic analyses, showing a close relation between them $[4,6]$. However, molecular information from other known species of the genus was unavailable. Eucoleus dubius is also in another category with RTI ornamentation.

In the genus Aonchotheca the RTII ornamentation predominates (Table 1). Although this ornament is observed in Baruscapillaria, Capillaria, Eucoleus and Tridentocapillaria, the frequency is not too high. The genus Echinocoleus exhibited RTI and punctuated ornamentations, but this cannot be assumed to be a pattern, as the genus had only two species studied. Pearsonema plica and $C$. collaris presented RTI ornamentation, although the egg morphology was different; one was narrowed on the extremity (Fig. 4g) and the other was rounder (Fig. 5c), respectively.

Regarding the statistical analysis of egg measures, no relation between genera was detected. The same was observed for discriminating species. Even though length showed more relevance than width, a large part of the measures overlapped, and it was impossible to discriminate among most of them. When discriminant analysis was employed using the dataset separated by ornamentations, only 5 species among 28 could be identified ( $E$. perforans, E. annulatus, E. eberthi, P. plica and A. baylisi). The results of discriminant analysis indicated the need to use a more robust tool that can integrate additional variables for species identification.

The ML/AI analysis revealed that when parameters related to geographical location and host were included, the reliability of the decision tree was higher with all algorithms used (Table 2). Although the LMT algorithm exhibited more reliable results, it did not produce a decision tree. Consequently, it is not functional in the biological sense and, more importantly, for application in future taxonomic identifications. The LMT algorithm would be useful if there was no need to understand how such taxonomic identification produced a specific classification.

Regarding ecological parameters, the $\mathrm{H}$ parameter may be more robust because, except for two genera (Capillaria and Eucoleus), it was possible to employ the taxonomic level of class and use one $\mathrm{H}$ entrance, avoiding decision errors. Regarding GL, first, for a more complete dataset, the parameter was defined by all the continents where the species was recorded, based on an extensive literature revision of capillariid identifications. However, species with worldwide distribution, such as $C$. hepaticum, presented multiple re-entrances in the dataset. The observed ML decision errors indicate that, whenever such worldwide distribution exists, it will be necessary to have additional egg features to improve the results. When using two different entrances for the same specimens, both for $\mathrm{H}$ and GL, the program tends to choose which one differentiates more between species. This could be erroneous because it does not consider the second entrance as a possible variable. For this reason, the GL parameter was then expressed as the site where specimens were collected, based on the FIOCRUZ and

\footnotetext{
(See figure on next page.)

Fig. 7 Decision tree for Capillaridae species discrimination using the J48 algorithm with MM $+\mathrm{GL}+\mathrm{H}$ parameters. MM: includes the attributes: length, width, plug base width, plug base height, shell thickness and ornamentation type (in orange). GL: geographic location includes North America, Central America, South America, Europe, Africa, Asia and Oceania (in green). H: includes fish, amphibians, reptiles, avians and mammals (in green). Ornamentation 1: smooth; 2: punctuated; 3: reticulated type I; 4: reticulated type II. Numbers in yellow are the capillariid species and in parentheses are correct/incorrect entries by the program. The numbers in the lines between the parameters represent the range of values considered to identify a specimen. Generated by Weka 3.8.3 software
} 


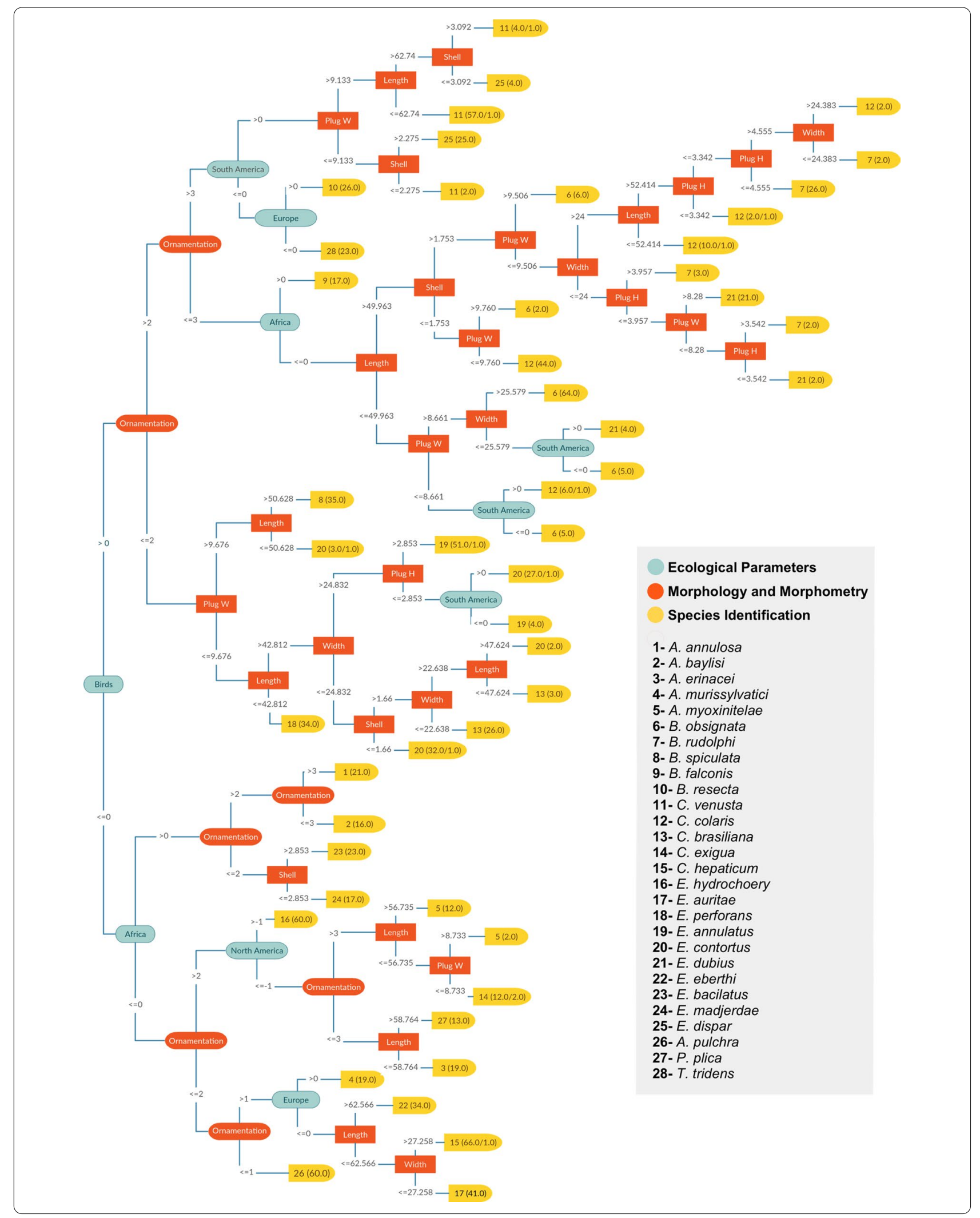


MNHN files. Therefore, the information on species distribution, used for geographical location, is restricted.

Although 12 decision trees were produced, as shown in Table 2, the trees generated by $\mathrm{MM}+\mathrm{GL}+\mathrm{H}$ exhibited the highest metric values in all algorithms (Fig. 7), with the exception of RandomTree where MM+GL displayed higher performance on most metric values. In general, GL showed the most relevant parameter in the presence of $\mathrm{H}$. These results revealed the relevance of ecological characteristics of specimens for the species discrimination. However, geographical location showed better results in all parameters compared to the host. No significant difference was shown between them $(\mathrm{MM}+\mathrm{H}$ or $\mathrm{MM}+\mathrm{GL}$ ), which means one could have compensated the absence of the other in those data. Otherwise, for the J48 algorithm, the Marascuilo test showed that the host had a significant difference from all parameters included, giving the notion that the GL is more reliable than $\mathrm{H}$. Moreover, we did not only consider the tree with MM as it had the worst metric performance.

Out of the three algorithms that produced a traditional decision tree, REPTree had the highest AUC value (0.986) and was statistically different from RandomTree (0.956), but not from J48 (0.979). Both REPTree and J48 algorithms were tested statistically with all the parameter combinations to see if we could find the best representation tree among them. In $\mathrm{J} 48 \mathrm{MM}+\mathrm{GL}+\mathrm{H}$ was statistically different from $\mathrm{MM}+\mathrm{H}$. Additionally, J48 had all the other metric values higher than REPTree (Table 2), and the parameters $\mathrm{MM}+\mathrm{GL}+\mathrm{H}$ had higher values than the other combinations, which affected our decision on representing the decision tree with J48 with all parameters.

One way to improve the result of the classifiers is to make a Majority Vote; as a result, the class with the highest number of votes is valid. There is a strong premise in this approach: it is assumed that voting entities will not err for the same classifications; in many situations, this can be assumed as true. However, when this approach was applied to the problem, we observed a drop in performance in relation to LMT, the best algorithm. This is possible because the expectation of the algorithms not to err for the same opinions has been frustrated, that is, the algorithms agree on their common mistakes. This might reflect the fact that the four algorithms belong to the same category of decision tree solvers. Thus, it makes sense that there is a possibility in this category for resolvers to induce some bias in agreeing to be correct in some cases and in agreeing to be wrong in other cases.

The Majority Voting algorithm, used to combine four algorithms, revealed higher metric values than J48, Random Tree and REPTree, with the exception of the AUC value, where REPTree (0.98) had a better performance. The LMT algorithm was the best algorithm in all metrics.
Even though the Majority Voting does not add value to the analysis, it allows us to understand how J48, Random Tree and REPTree work. The fact that the Majority Voting had lower metric values than the LMT says that the contribution of the three other algorithms hinders the results, which suggests the three algorithms are wrong in the same cases. This makes them the majority, and the final decision becomes wrong. Therefore, while the LMT algorithm is right, the Majority Voting is wrong because of that wrong majority decision. It also cannot be used as a taxonomic key for the same reason as the LMT, discarding their application for the article's purpose.

The ML/AI approach have been recently used to analyze the relationships among Strongyloides genotypes using multi-locus sequence typing, considering hosts and geographic distribution. This analysis showed the presence of different populations that were not evident using smaller datasets [13], corroborating the importance of a bigger dataset and the use of ML/AI in the classification of helminths.

The present study has some limitations relating to the dataset. It contains 28 species and 8 genera of capillariids out of more than 300 species and 25 genera described. Therefore, it contributes with a small portion of the real scenario of the biological diversity in capillariids. Despite about 30 eggs each examined, some species are represented by one specimen, what could be a restriction in the possible intraspecific and ecological variations. In addition, multiple hosts or geographical origins in the same species could be interpreted by the system as a discrepant character and, consequently, the learning is wrongly addressed. However, capillariid species in general are not so restricted. The solution we found was both a generalization and constriction of information on host and geographical location, respectively. The addition of new curated information from other biological helminth collections will enable the construction of a stronger, well-supported dataset and a better taxonomic definition using ML/AI. To our knowledge, this study is the first to apply artificial intelligence techniques to the taxonomic definition of biological species, opening an opportunity of application in health, biodiversity and technology research in other important taxa.

\section{Conclusions}

The machine learning/artificial intelligence approach presented herein is an initial methodology for parasite species identification using capillariids as a model. The present study makes available a solid representation of capillariids deposited in two large and diverse institutional collections of the world, CHIOC/FIOCRUZ and Collection de Nématodes Zooparasites/MNHN. It supports the identification of capillariids with the 
characterization of 28 species and 8 genera, generating a catalog for future references. Furthermore, it supplies new data in the characterization of nematode eggs, a field that lacks knowledge in parasite morphological description, which comprises ecological and health surveys, as well as paleoparasitological research. Other collections can apply the same ML/AI methodologies proposed here and increase the species and families described.

\begin{abstract}
Abbreviations
ML: Machine learning; CHIOC: Coleção Helmintológica do Instituto Oswaldo Cruz; IOC: Instituto Oswaldo Cruz; FIOCRUZ: Fundação Oswaldo Cruz; MNHN: Muséum National d'Histoire Naturelle de Paris; MM: Morphological and morphometric values; GL: Geographical location; H: Host; LMT: Logistic model trees; Al: Artificial intelligence; RTI: Reticulated type I; RTII: Reticulated type II; AUC: Area under the receiver-operating characteristic curve; ROC: Receiveroperating characteristic; NPV: Negative predictive value; PPV: Positive predictive value.
\end{abstract}

\section{Supplementary Information}

The online version contains supplementary material available at https://doi. org/10.1186/s13071-021-04721-6.

Additional file 1: Table S1. Morphometry: measurements of length, width, plug width, plug thickness and shell thickness; morphology: shell ornamentations, 1, smooth; 2, punctuated; 3, reticulated type I; 4, reticulated type II; host: fish, amphibian, reptile, avian, mammals; geographical location: South America, Central America, North America, Europe, Africa, Asia, Oceania. Response variable were $1=$ yes or presence, $0=$ no or absence, and $-1=$ no information. Table S2. Results of statistical analysis using AUC values performed on RStudio version 3.5.1. P-value of the Chi-square statistic among algorithms and combination of parameters applied. Marascuilo test results on the comparison of combination of parameters $(\mathrm{MM}+\mathrm{GL}, \mathrm{MM}+\mathrm{H}, \mathrm{MM}+\mathrm{GL}+\mathrm{H})$ per algorithm (J48, Random Tree, REPTree, LMT and Majority Voting) and on the comparison of algorithms per combination of parameters applied. Table S3. Confusion Matrices generated by Weka 3.8.3 software showing the false positives, false negatives and true negatives resulted from each algorithm ( $J 48$, REPTree, Random Tree, LMT and Majority Voting) of each combination of parameters $(\mathrm{MM}+\mathrm{GL}+\mathrm{H}, \mathrm{MM}+\mathrm{GL}, \mathrm{MM}+\mathrm{H}$ and $\mathrm{MM})$.

Additional file 2: Figure S1. Decision trees generated by Weka software using the $\mathrm{J} 48$ algorithm, including trees with the parameter $\mathrm{MM}+\mathrm{GL}$ (Fig. 1), MM + H (Fig. 7), MM for P ornamentation (Fig. 2), MM for RTI ornamentation (Fig. 3) and MM for RTII ornamentation (Fig. 4). Generated by Weka 3.8.3 software. Figure S2. Taxonomic Key of eggs of Capillariidae created from the tree generated by Weka using the J48 algorithm and $\mathrm{MM}+\mathrm{GL}+\mathrm{H}$ parameters.

\section{Acknowledgements}

We would like to thank the staffs of the Helminth Collection of Oswaldo Cruz Institute from Oswaldo Cruz Foundation (CHIOC/FIOCRUZ), and of the Collection de Nématodes Zooparasites from National Museum of Natural History of Paris (MNHN). We also thank Marcelo Pires for the availability and assistance for the statistical analysis.

\section{Authors' contributions}

VHB and AMI designed the study. VHB performed the experiments and wrote the first version of the manuscript. FLM supervised the machine learning/artificial intelligence analyses. SX performed the statistical analyses. CM and JRM-S provided the parasitological expertise. VHB and AMI analyzed the results and wrote the final version of the manuscript. All authors read and approved the final manuscript.

\section{Funding}

The present study was supported by grants-in-aid and fellowship from Fundação de Amparo à Pesquisa do Rio de Janeiro (http://www.faperj.br/) (AMI, Grant Number 26/202.945/2016) (SX, Grant Number E-26/210.145/2017); fellowships from Conselho Nacional de Desenvolvimento Científico e Tecnológico (http://www.cnpq.br/) (AMl, Grant Number 312934/2017-3) (JRM-S, Grant Number 470724/2014-5) (SX, Grant Number 422489/2018-2); grants-in-aid and fellowships from Coordenação de Aperfeiçoamento de Pessoal de Nível Superior (http://www.capes.gov.br/) (AMI and VHB, grant number 23038000059/2015-61) and grants-in-aid and fellowships from the COFECUB research and cooperation program (https://www.campusfrance. org/fr/cofecub) (AMI, CM and VHB, grant number 33387UA) fellowship from Fundação Coordenação de Projetos, Pesquisas e Estudos Tecnológicos (http:// www.coppetec.coppe.ufrj.br) (FLM Poli 19257). The funders had no role in study design, data collection and analysis, decision to publish, or preparation of the manuscript.

\section{Availability of data and materials}

All data generated or analysed during the present study are included in this article and its additional files.

\section{Declarations}

Ethics approval and consent to participate

Not applicable.

\section{Consent for publication}

Not applicable.

\section{Competing interests}

The authors declare that they have no competing interests.

\section{Author details}

${ }^{1}$ Laboratório de Biologia de Tripanosomatídeos-LABTRIP, Instituto Oswaldo Cruz, IOC-FIOCRUZ, Rio de Janeiro, RJ, Brazil. ${ }^{2}$ Laboratório de Helmintologia Romero Lascasas Porto, Faculdade de Ciências Médicas, UERJ, Rio de Janeiro, RJ, Brazil. ${ }^{3}$ Unité Molécules de Communication et Adaptation des Microorganismes (MCAM, UMR 7245), Muséum National d'Histoire Naturelle, CNRS, CP52, Paris, France. ${ }^{4}$ Departamento de Engenheira Eletrônica e Computação, Universidade Federal do Rio de Janeiro, Rio de Janeiro, RJ, Brazil.

Received: 27 August 2020 Accepted: 7 April 2021

Published online: 01 May 2021

\section{References}

1. Moravec F. Proposal of a new systematic arrangement of nematodes of the family Capillariidae. Folia Parasitol (Praha). 1982;29:119-32.

2. Moravec F, Prokopic J, Shlikas A. The biology of nematodes of the family Capillariidae Neveu-Lemaire, 1936. Folia Parasitol (Praha). 1987;34:39-56.

3. Gibbons LM. Keys to the nematode parasites of vertebrates: supplementary volume. Wallingford: CAB International; 2010.

4. Tamaru M, Yamaki S, Jimenez LA, Sato H. Morphological and molecular genetic characterization of three Capillaria spp. (Capillaria anatis, Capillaria pudendotecta, and Capillaria madseni) and Baruscapillaria obsignata (Nematoda: Trichuridae: Capillariinae) in avians. Parasitol Res. 2015;114:4011-22.

5. Guardone L, Deplazes P, Macchioni F, Magi M, Mathis A. Ribosomal and mitochondrial DNA analysis of Trichuridae nematodes of carnivores and small mammals. Vet Parasitol. 2013;197:364-9.

6. Borba VH, Machado-Silva JR, Le Bailly M, Iñiguez AM. Worldwide paleodistribution of capillariid parasites: paleoparasitology, current status of phylogeny and taxonomic perspectives. PLoS ONE. 2019;14:4.

7. Iñiguez AM. Ancient DNA and paleoparasitology in Brazil. In: Shin DH, Bianucci $R$, editors. The handbook of mummy studies new frontiers in scientific and cultural perspectives. Singapore: Springer; 2021. p. 1-34.

8. Romashov B. Morphological peculiarities of egg shell in capillariids (Nematoda, Capillariidae). Parazitologiia. 1985;5:399-401. 
9. de Mello FL, de Souza SA. Psychotherapy and artificial intelligence: a proposal for alignment. Front Psychol. 2019;10.

10. Lopez DM, de Mello FL, Giordano Dias CM, Almeida P, Araújo M, Magalhães MA, et al. Evaluating the surveillance system for spotted fever in Brazil using machine-learning techniques. Front Public Health. 2017;5.

11. Bhagyashree SIR, Nagaraj K, Prince M, Fall CHD, Krishna M. Diagnosis of dementia by machine learning methods in epidemiological studies: a pilot exploratory study from south India. Soc Psychiatry Psychiatr Epidemiol. 2018:53:77-86.

12. Wheeler NE, Gardner PP, Barquist L. Machine learning identifies signatures of host adaptation in the bacterial pathogen Salmonella enterica. PLOS Genet. 2018;14:5.

13. Barratt JLN, Sapp SGH. Machine learning-based analyses support the existence of species complexes for Strongyloides fuelleborni and Strongyloides stercoralis. Parasitology. 2020;147:1184-95.

14. Borba V, Enoki M, Lopes-Torres EJ, Machado-Silva JR, Iñiguez AM. New data on eggshell structure of capillariid species: a SEM perspective. Parasitol Res. 2021;120:963.

15. Conboy G. Helminth Parasites of the Canine and Feline Respiratory Tract. Vet Clin North Am Small Anim Pract. 2009:39:1109-26.

16. Traversa $D$, Cesare AD, Milillo P, lorio R, Otranto D. Infection by Eucoleus aerophilus in dogs and cats: is another extra-intestinal parasitic nematode of pets emerging in Italy? Res Vet Sci. 2009;87:270-2.

17. Zajac A, Conboy GA. Veterinary clinical parasitology. 8th ed. Chichester: Wiley-Blackwell; 2012

18. Eibe F, Hall MA, Witten IH. Data mining: practical machine learning tools and techniques. 4th ed. USA: Morgan Kaufmann; 2016.

19. Quinlan R. C4.5: Programs for machine learning. San Mateo: Morgan Kaufmann Publishers; 1993
20. Aldous D. The continuum random tree. I Ann Probab. 1991;19:1-28.

21. Elomaa T, Kaariainen M. An analysis of reduced error pruning. J Artif Intell Res. 2001:15:163-87.

22. Landwehr N, Hall M, Frank E. Logistic model trees. Mach Learn. 2005:59:161-205.

23. Kittler J, Hatef M, Duin RPW, Matas J. On combining classifiers. IEEE PAMI. 1998;20:226-39.

24. Kondeti PK, Ravi K, Mutheneni SR, Kadiri MR, Kumaraswamy S, Vadlamani $\mathrm{R}$, et al. Applications of machine learning techniques to predict filariasis using socio-economic factors. Epidemiol Infect. 2019;147.

25. Spratt DM. Description of capillariid nematodes (Trichinelloidea: Capillariidae) parasitic in Australian marsupials and rodents. Zootaxa. 2006;1348:1-82.

26. Moravec F. Redescription and systematic status of Capillaria philippinensis, an intestinal parasite of human beings. J Parasitol. 2001;87:161-4.

27. Poulin R. The evolution of life history strategies in parasitic animals. Adv Parasitol. 1996;37:107-34.

28. de Souza MV, da Silva LGR, Silva-Pinto V, Mendez-Quiros P, de Miranda Chaves SA, Iñiguez AM. New paleoparasitological investigations from the pre-Inca to Hispanic contact period in northern Chile. Acta Trop. 2018;178:290-6.

29. Hodžić A, Alić A, Klebić I, Kadrić M, Brianti E, Duscher GG. Red fox (Vulpes vulpes) as a potential reservoir host of cardiorespiratory parasites in Bosnia and Herzegovina. Vet Parasitol. 2016;223:63-70.

\section{Publisher's Note}

Springer Nature remains neutral with regard to jurisdictional claims in published maps and institutional affiliations.
Ready to submit your research? Choose BMC and benefit from:

- fast, convenient online submission

- thorough peer review by experienced researchers in your field

- rapid publication on acceptance

- support for research data, including large and complex data types

- gold Open Access which fosters wider collaboration and increased citations

- maximum visibility for your research: over 100M website views per year

At BMC, research is always in progress.

Learn more biomedcentral.com/submissions 